\title{
The Neo-Industrial Role of Digital and Converged Technologies in the Russian Economy
}

\author{
Natalia Ezdina*, and Elena Dotsenko \\ Plekhanov Russian University of Economics, 117997 Moscow, Russia
}

\begin{abstract}
In modern conditions, the diffusion of digital technologies into the structure of the economy is considered as one of the most effective mechanisms for transforming economic systems. The digital economy as a category has a wide content, since, in addition to production and technological features, it also includes social, economic, institutional parameters that ensure the transition to a new scientific and technological structure, characterized by the integration and interpenetration of sciences and technologies - technological convergence. In the process of diffusion of convergent technologies into the structure of the industry, its radical innovative development is expected with an exit to many times higher levels of labor productivity. This process should be called neo-industrial development, in which structural changes in industry are not sectoral, but over sectoral, convergent. At the same time, in the conditions of the transitional Russian economy, the conducted scientific and technological policy is essentially catching up and is not able to ensure the elimination of technological lag. Therefore, to implement the neo-industrial role of digital and convergent technologies in the modernization of the Russian economy, it is important to ensure the transition to a policy of advanced development.
\end{abstract}

\section{Introduction}

In Russia the market reforms have caused a de-industrial trend - the consolidation of the role of a raw materials supplier to the world market, the destruction of the technological base with a decrease in the share of the industrial and manufacturing complex in the economy structure, as well as a drop in the development indices of the research sector. The need to ensure technological parity with developed countries dictates the necessity to comprehend the role of the latest technologies - convergent ones - based on the digital transformation of Industry 4.0 branches (biochemistry and genetic engineering, nanomaterial and robotics, bioenergy, cognitive computing systems) for the radical modernization of the manufacturing sector on a new technological basis [1].

In the course of neo-industrial development of the national economy under the influence of digitalization factors and the expansion of convergent technologies, traditional industrial sectors face the following tasks [2]:

- innovative digital transformation of basic sectors of the economy for a radical increase in labor productivity;

\footnotetext{
* Corresponding author: ezdinanp@list.ru
} 
- the use of new factors of production - digital technologies converging with artificial intelligence (cognitive technologies), nano- and biotechnologies;

- accelerated diffusion of new technological solutions in the direction of NBIC convergence (nano-, bio-, information, cognitive technologies);

- priority development of information technologies as the basis for convergent technological modernization of the economy in the process of neo-industrial development;

- increasing the diffusion rate of digital technologies in industry.

\section{Materials and Methods}

The place of digital technologies in neo-industrial development is determined by their key role in combining convergent technologies with their specific principle of supra-industry functioning, and the production capabilities of basic industries. The concept of "digital economy" as an economic category, reflecting the trends in the penetration of advanced production technologies and new business models into the formation of competitive structures in the global economy, was introduced by Nicholas Negroponte in 1996 [3]. An American computer scientist drew an analogy with the transition from processing atoms to processing bits. As the shortcomings of the economy in its traditional understanding, he noted the presence of the weight of goods, raw materials and a transport component. According to $\mathrm{N}$. Negroponte, the advantages of the digital economy are the absence of weight of goods, the minimum need for raw materials, virtuality and instant logistics.

To determine the forms and tools of research and technological policy in the context of the expansion of digital technologies and intersectoral convergence, it is necessary to highlight its main models [4-6], which have been formed to date:

- compensation policy aimed at conservation of the existing technological level at large industrial enterprises. It implicates fixing the achieved level of digitalization and is to support companies which are important for the industry during crises. Technological breakthroughs are not a priority here;

- the policy of catch-up development, aimed at overcoming the technological lag behind the countries - the closest competitors in the domestic market. At the same time, digitalization affects the most competitive industries, but does not correspond to the world level of technological development. As a rule, the main recipients of tax breaks, subsidies and government investments are large holding companies that are leaders in the domestic market;

- a policy of advanced development aimed at achieving technological leadership in the foreign market. Within the framework of such a technological policy, there is no pronounced sectoral orientation of tax, credit, investment incentives, and subsidies. The advanced development policy presupposes fundamentally new tax and investment regimes applied to a large number of large, medium and small firms that create the basis for the digitalization of industry.

With regard to neo-industrial development, compensation policy can become an obstacle to the innovative modernization of basic industries, since it fixes the low technological efficiency of large companies. The policy of catching-up technological development also cannot be called neo-industrial, since its selective focus entails the demonetization of production and a decrease in demand for innovations. The reason for this, as a rule, is the impossibility of creating modern digital technologies in the country, as well as the import of obviously outdated technologies. As a result, the policy of catching-up development increases the technological dependence of the national economy.

In contrast to them, the policy of advanced development is aimed at the diffusion of new technologies into the economy structure, the transfer of successful technological 
developments from the level of individual firms to the macro level. However, despite the obvious long-term advantages, in the short term, the policy of advanced technological development has a high degree of uncertainty and risks typical for the digital economy of developed countries (market, technical, systemic).

The study of the digital modernization problems in the Russian industry as a driver of neo-industrial development of the economy showed a predominantly catching-up type of technological policy, which in recent years has been changing to compensatory [7]. To determine the parameters of the new paradigm of industrial policy, it is necessary to assess the degree of correlation between the identified priorities of scientific and technological development in Russia with specific measures for the formation of the digital economy. The last document in chronological order that defines the priority areas in this field is the Order of the Government of the Russian Federation of July 28, 2017, No. 1632-r "On the approval of the program "Digital Economy of the Russian Federation" [8], as well as "Strategy of scientific and technological development of the Russian Federation until 2035", approved by the Decree of the President of the Russian Federation dated 01.12.2016, No. 642 [9]. However, the priorities outlined in the Strategy are not detailed, and specific technological directions for the formation of the digital economy are not indicated. Based on the objectives of this study, it seems appropriate to consider in more detail the section "Development of High Technologies" presented by the target program of the same name.

The volume of funding for the federal target program "Development of High Technologies" in relative terms in a scope of the priorities of digitalization of the Russian economy is quite significant (in $2015-44.9 \%$ and $2014-57.2 \%$ of all expenses (private and state) for the acquisition of digital assets) [9]. However, in absolute terms, the volume of budget financing of the target program "Development of High Technologies" in 2018 is one of the lowest among other target programs. At the same time, since 2013, the volume of government incentives for the development of the digital economy has been steadily declining (Fig. 1).

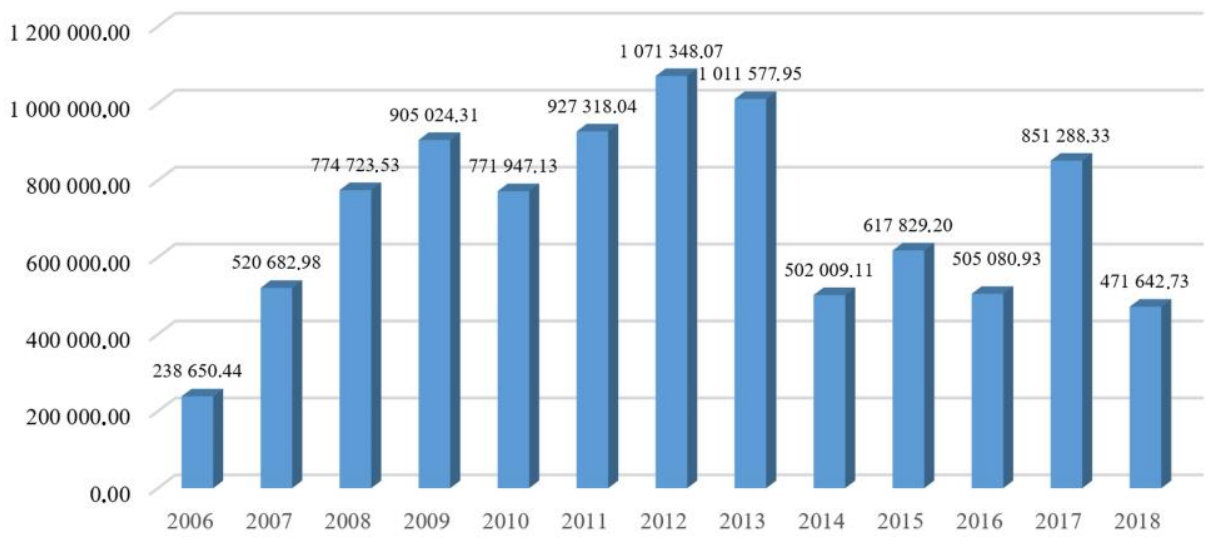

Fig. 1. Volumes of budgetary financing of the Russian federal target program "Development of High Technologies", billion rubles. [9]

The data shown in Fig. 1 indicate a discrepancy between the strategic priorities in the field of the digital economy and real programs designed to implement the state policy in practice, and, as a consequence, the complete absence of correlation between the digitalization policy and the paradigm of a promising technological layer. In the context of the dependence of the Russian economy on foreign digital and convergent technologies, it is necessary to focus on the development of its own technological base. Taking into 
cosidereation the degree of technological lag, its reduction seems possible due to revolutionary technological development, which presupposes advanced actions to create fundamentally new markets for convergent technologies, which will finally dominate in 15 20 years [10]. However, taking into account the high risks of catching-up technological development it is advisable to include convergent technological modernization and digitalization of the basic sectors of the Russian economy into the priorities of structural policy.

\section{Results and Discussion}

In the context of neo-industrial development, the digital economy appears, on the one hand, as a locomotive for the innovative development of basic industries to the level of Industry 4.0 [11]. On the other hand, the digital economy creates a reproductive basis for the introduction and cross-sectoral diffusion of convergent technologies, which will determine national competitiveness at the stage after Industry 4.0 [12]. Therefore, we have defined the digital economy as a fundamentally new system of economic relations, which involves not only the production of goods and the provision of services using digital technologies, but also the transformation of the structure of industry, government, and the social sphere as a result of receiving digital dividends. Digital dividends are understood as the benefits arising from digitalization - these are economic and social effects. The economic effects include:

1. Acceleration of economic growth as a result of radical growth in labor productivity in all sectors of the economy. Modern digital technologies open up new business opportunities: barriers to entry for new enterprises are significantly reduced, and innovation is accelerated through increased competition. World trade is becoming more integrated system; markets and geography of sales are expanding thanks to platform companies. Information and communication technologies can significantly optimize business processes, reduce costs and increase the efficiency of the production cycle. A prime example is the American logistic company UPS, which, by automating routes in such a way as to avoid left turns, reduces travel time and thereby saves up to 4.5 million liters of gasoline every year. In addition, the Internet provides open access to information and, because of permanent price competition, goods and services become more accessible to end users.

2. Reduction of production and investment cycles. Digital technologies are aimed at optimizing all business processes and allow reducing the duration of production operations. For Russia today, this indicator is more relevant than ever because over the past five years labor productivity has grown by $8 \%$ [13], which is a low indicator compared to dynamically developing countries.

3. Creation of new jobs. The digital economy itself is not capable of generating a huge number of jobs, however, at the same time, labor in it is, as a rule, highly paid, which has a positive synergetic effect. Statistics show that in the United States one high-tech job creates 4.9 jobs in other sectors of the economy [14]. Employment is increasing not only due to the emergence of large trading platform companies, but also due to the emergence of great opportunities for self-employment and the provision of remote work for certain categories of the population.

The social effects of neo-industrial development based on technological convergence and full-scale digitalization of the economy and society include:

- improving the quality and availability of goods and services to consumers. Competition forces manufacturers to constantly improve the consumer properties of their products and reduce prices. It should be noted that in addition to traditional goods and services, transformations should also affect such socially significant sectors as education and medicine; 
- increasing the efficiency of the public sector. Providing services to the population through E-Government helps to reduce the corruption component, improve feedback, integrate interdepartmental structures, increase the transparency of government agencies (posting information on purchases, budgets and corporate reporting indicators), and modernize urban infrastructure. For example, SeeClickFix and FixMyStree mobile applications, deployed in the United States and the United Kingdom, enable users to report problems in the urban environment such as pits on the roads, landscaping disturbances, illegal dumps and receive information from the authorities about the actions taken. [15] In a number of countries, the experiment in introducing digital technologies into the public sector has gone further. In Iceland, a collective drafting of the country's constitution was carried out, in Brazil and Estonia, a process of drafting laws with the direct participation of the population;

- strengthening social integration. First, digital technologies allow people with disabilities or those living in remote areas to work remotely, get an education, etc. Second, digital technologies facilitate the participation of the poor, who often do not have identity documents, in public and political life. In India, more than 900 million citizens have received digital IDs over the past five years, which allow them to use banking services and to claim government benefits [16].

Digital technologies contribute to a radical transformation of the structure of the economy, there is not only a qualitative technological update, but also a modification of the labor market, property relations, the production cycle, the mechanisms of economic activity, the model of added value formation and other structural elements undergo changes. In this regard, despite the obvious advantages and possible economic and social effects of digitalization, there are also possible risks and threats associated with the introduction of information and communication technologies:

- an increase in unemployment and an increase in the cost of training and advanced training of employees. Despite the fact that digital technologies give rise to new professions in the information and communication technology industry and the creation of jobs in related industries, significant automation of all business processes will inevitably lead to job losses. According to some experts, up to $30 \%$ of traditional professions, such as a driver, legal adviser, estimator, librarian, tour guide, accountant, will disappear in the next 10-20 years [17]. In addition, significant investments in human capital will be required due to the need to retrain personnel;

- strengthening the differentiation of incomes and living standards of the population. The digital mode of operation of most enterprises will inevitably lead to a significant reduction or complete replacement of routine work with high-tech equipment. As a result, the incomes and living standards of low-skilled workers may decline, while highly qualified personnel will have a significant competitive advantage with an increase in the share of automated production processes. At the same time, it is precisely technological progress that can multiply the labor productivity and the task of the state is to pursue a competent social policy that neutralizes the emerging differentiation;

- the complexity of regulating relations between economic entities that arise within the digital economy. There is a need for legal regulation to provide a favorable environment for economic activities related to the development and implementation of digital technologies.

In this model of the reproduction system of the digital economy, crowd technologies crowdinvesting and crowdlending - can be distinguished as alternative private financing instruments. The model of open digital innovation assumes crowdsourcing as one of the tools for actively attracting innovations and competencies. In foreign practice, this concept has been implemented for several decades; in Russia, the application of the open innovation paradigm is only gaining popularity. Despite the variety of possible forms of interaction between economic agents within the framework of such a mechanism of economic activity, there are a number of barriers to the introduction of the open innovation model as a form of 
a network mechanism. The main limitations are associated with the imperfection of the regulatory framework in matters of intellectual property protection, joint activities and developments, as well as difficulties in finding partners. Overcoming these barriers to open digital innovations is also the task of advanced development policy.

\section{Conclusion}

The digital paradigm of the transition to advanced scientific and technical policy involves the interaction of the private and public sectors as strategic cooperation in industrial production, the transition from industry orientation to focus on specific firms, minimization of barriers to technology transfer, consumer involvement in the production process, rejection of large-scale production based on economy of scale.

The main directions of state industrial policy are digital modernization and convergent technological diversification of the industrial structure, where industrial technologies are synthesized with technologies of a new type, and ensuring the development of "breakthrough" sectors.

Structural priorities are the implementation of new technological breakthroughs based on digital technologies of a new type, an orientation towards the formation of new markets and sectors that will come in force in 15-20 years. Possible economic and social effects from the diffusion of digital technologies into the economy structure (as technologies of a convergent type with the greatest integration potential) are manifested in economic growth as a result of increasing efficiency of all economic entities, labor productivity, creation of new jobs, increasing the quality and availability of goods and services for consumers, increasing the efficiency of public sector, environmental well-being and strengthening social inclusion.

\section{References}

1. M. C. Roco, W. S. Bainbridge, Converging technologies for improving human performance: nanotechnology, biotechnology, information technology and cognitive science (2003)

2. E. Dotsenko, N. Ezdina, D. Caganova, S. Mudrova, E3S Web Conf., 174, 04039 (2020)

3. N. Negroponte, Being Digital (1996)

4. N. Ezdina, E3S Web of Conferences, 21, 04015 (2017)

5. S. Zhironkin, D. Khloptsov, N. Skrylnikova, I. Petinenko, O. Zhironkina, E3S Web Conf., 41, 04010 (2018)

6. A. L. Volkova, O. U. Korneva, Economics and Innovation Management, 2, 32 (2019)

7. S. K. Demchenko, M. S. Zlotnikov, T. A. Melnikova, O.S. Demchenko, Int. J. of Civil Engineering and Technology, 10(2), 1877 (2019)

8. Order of the Government of the Russian Federation of July 28, 2017 No. 1632-r "On approval of the program "Digital Economy of the Russian Federation" (2017)

9. Strategy of scientific and technological development of the Russian Federation until 2035. Approved by the Decree of the President of the Russian Federation of 01.12.2016 No. 642 (2016)

10. M. Kose, Ch. Otrok, E. S. Prasad, NBER Working Paper, 14292, 234 (2008)

11. S. Zhironkin, O. Aleshina, V. Gorev, Y. Gunyakov, O. Zhironkina, E3S Web Conf., 105, 04001 (2019)

12. A. Balabanova, V. Balabanov, E. Dotsenko, N. Ezdina, E3S Web Conf., 15, 04013 (2017) 
13. E. V. Slesarenko, Economics and Innovation Management, 4, 4 (2018)

14. E. Rogers Diffusion of Innovations (2010)

15. M. T. Borsi, N. Metiu, Empirical Economics, 4, 657 (2015)

16. Dreaming With BRICs: The Path to 2050 (2017)

17. M. Klimovich, M. A. Gasanov, Economics and Innovation Management, 2, 8 (2019) 